\title{
PENERAPAN KOREKSI TOPOGRAFI PADA DATA MAGNETOTELLURIK DAN ANALISIS DATA GAYA BERAT DALAM INTERPRETASI \\ DAERAH PANAS BUMI PANTAR, KABUPATEN ALOR, PROVINSI NUSA TENGGARA TIMUR
}

\section{TOPOGRAPHY CORRECTION OF MAGNETOTELLURIC DATA AND GRAVITY DATA ANALYSIS IN PANTAR GEOTHERMAL AREA, ALOR REGENCY, EAST NUSA TENGGARA PROVINCE}

\author{
Tony Rahadinata, Iqbal Takodama, dan Ahmad Zarkasyi \\ Pusat Sumber Daya Mineral, Batubara Dan Panas Bumi \\ tony.rahadinata@gmail.com
}

\begin{abstract}
ABSTRAK
Pantar berada pada lingkungan vulkanik Kuarter yang memiliki potensi panas bumi yang diindikasikan dengan adanya manifestasi panas bumi berupa fumarola, solfatara, tanah panas dan air panas. Survei geofisika magnetotelurik (MT) dan gaya berat dilakukan untuk mengklarifikasi sistem panas bumi di daerah ini. Teknik pemodelan data MT menggunakan inversi 3 dimensi (3-D) dengan dan tanpa koreksi topografi untuk optimalisasi hasil. Pemisahan anomali Bouguer pada metode gaya berat dilakukan dengan teknik trend surface analysis dan upward continuation. Hasil pemodelan MT dan gaya berat akan dikombinasikan untuk menginterpretasi sistem panas bumi. Penerapan koreksi topografi pada inversi 3D data MT yang dikombinasikan dengan metode gaya berat memberikan hasil yang lebih optimal. Kedua hasil metode tersebut secara jelas menunjukkan keberadaan lapisan penudung, zona reservoir dan sumber panas. Lapisan bertahanan jenis rendah yang diinterpretasikan sebagai lapisan penudung termodelkan di sekitar Gunung Beang sampai dengan kedalaman 750 meter. Lapisan bertahanan jenis medium yang diinterpretasikan sebagai zona reservoir dimodelkan mulai kedalaman 750-1000 meter. Zona anomali tinggi yang termodelkan pada kedua metode mempertegas adanya tubuh vulkanik muda yang diinterpretasikan sebagai sumber panas sistem panas bumi.
\end{abstract}

Kata kunci: Pantar, Panas Bumi, Koreksi Topografi, Gaya Berat, Magnetotelurik.

\begin{abstract}
Pantar is located in Quaternary volcanic environment which has geothermal potential, indicated by the presence of geothermal manifestations such as fumarol, solfatar, hot ground and hot spring. Magnetotelluric (MT) and gravity surveys were carried out to clarify geothermal system in this area. Modelling technique of MT data used 3-dimentional (3-D) invertion process with and without topographic correction to enhance the result. Filtering Bouguer anomaly in gravity method used trend surface analysis and upward continuation techniques. Those two modelling process of MT and gravity data were combined to interpret the geothermal system. Application of topographic correction on 3-D inversion of MT data which combined with gravity method give procuced optimum result. The result of those two methods shows clearly the existance of caprock, reservoir zone and high anomaly zone which indicates of young volcanic body as heat source in this geothermal system. Low resistivity zone, interpreted as cap rock, is modeled near Mount Beang until 750 meter depth. Medium resistivity zone, interpreted as reservoir zone, is modeled from 750-1000 meter depth. The high anomaly zone, is modeled in both method emphasized existence of young volcanic body interptred as a heat source of geothermal system.
\end{abstract}

Keywords: Pantar, geothermal. topographic correction, gravity, magnetotelluric 


\section{MAKALAH ILMIAH}

\section{PENDAHULUAN}

Daerah panas bumi Gunung Sirung atau Pulau Pantar berada di wilayah Kabupaten Alor, Provinsi Nusa Tenggara Timur. Keberadaan sistem panas bumi di daerah ini tampak dengan adanya manifestasi panas bumi berupa fumarola, solfatara, tanah panas, air panas bertemperatur mencapai $98{ }^{\circ} \mathrm{C}$ dan batuan teralterasi. (Gambar 1).

Daerah panas bumi ini berada pada lingkungan vulkanik Kuarter. Aktivitas vulkanik Gunung Sirung diperkirakan sebagai sumber panas dari sistem ini. Batuan penyusun daerah survei didominasi oleh batuan vulkanik (Hadi dkk, 2015). Stratigrafi batuan tersusun oleh produk erupsi vulkanik dan batuan sedimen. Batuan tertua terbentuk pada Tersier Akhir berupa vulkanik yang tersebar di pesisir pantai utara dan timur diikuti oleh pengendapan batuan sedimen (batugamping terumbu di bagian tengah). Struktur geologi memisahkan kedua produk vulkanik tua tersebut dengan arah hampir utara selatan (Gambar 2). Struktur geologi didominasi oleh arah tegasan utara - selatan sebagai sesar utama. Pola tersebut berhubungan dengan arah tektonik regional yang berkembang di daerah Pulau Pantar- Pulau Alor.
Survei geofisika untuk mengetahui sistem panas bumi di Pantar dilakukan dalam rentang waktu 2015 sampai dengan 2017. Metode gaya berat daerah ini diambil pada tahun 2015 dan dilanjutkan pada tahun 2016 dan 2017 dengan menggunakan metode magnetotelurik (MT).

Hasil geofisika sangat tergantung pada proses pengolahan data. Banyak teknik pengolahan data yang dapat digunakan dalam proses data geofisika. Pemilihan teknik ini bertujuan mendapatkan hasil yang optimal yang dapat digunakan dalam interpretasi sistem panas bumi. Oleh karena itu untuk optimalisasi data geofisika ini maka diperlukan kombinasi lebih dari satu metode geofisika.

Penulisan makalah ini bertujuan untuk mengaplikasikan teknik alternatif dalam pengolahan dan analisis data MT. Hasil yang diperoleh dari proses pengolahan data MT akan dikombinasikan dengan data gaya berat. Teknik pengolahan data MT yang dilakukan berupa pemodelan inversi tiga dimensi (3-D) dengan dan tanpa koreksi topografi. Hasil MT akan dikombinasikan dengan hasil gaya berat sebagai metode untuk memperkuat hasil yang diperoleh dari berbagai teknik proses pengolahan data MT tersebut. Hasil kombinasi kedua metode akan digunakan dalam menginterpretasi sistem panas bumi.

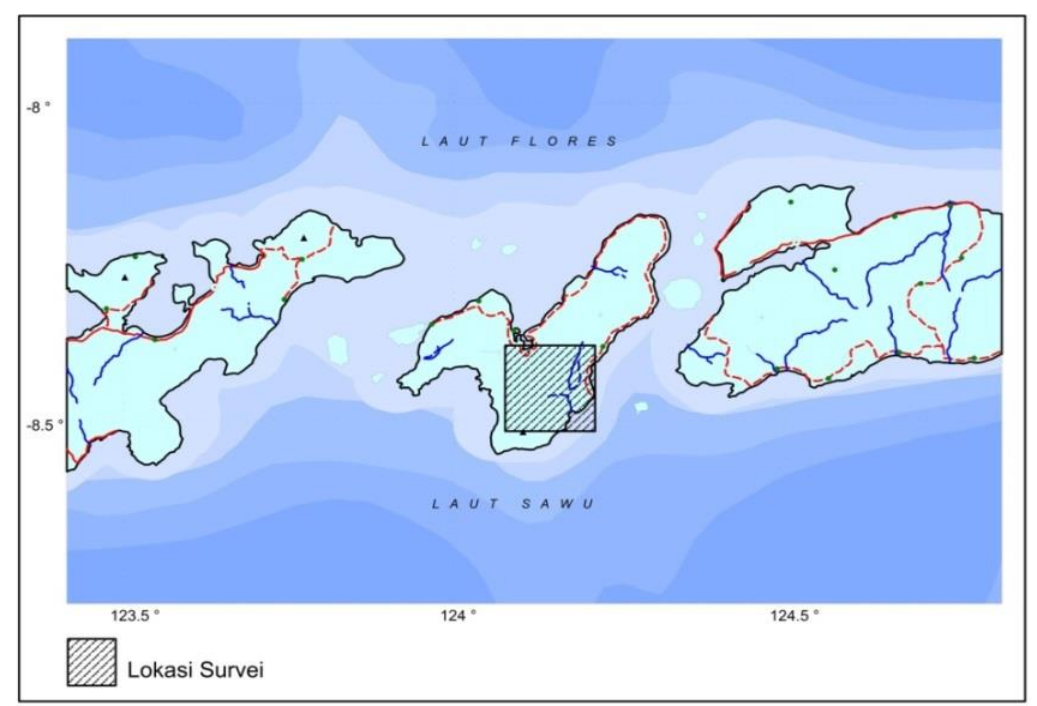

Gambar 1. Peta lokasi penelitian 


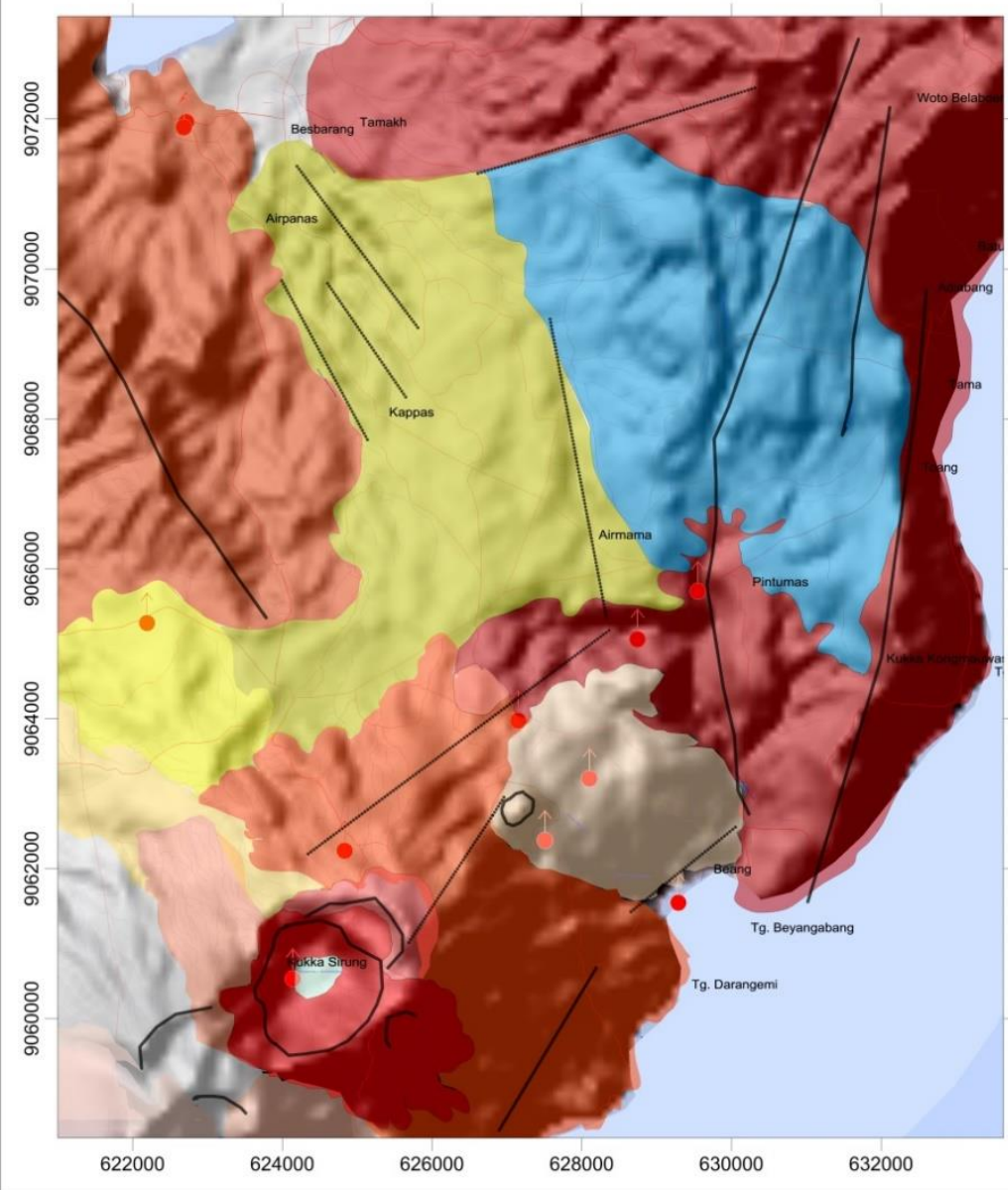

\section{PETA GEOLOGI DAERAH PANTAR}

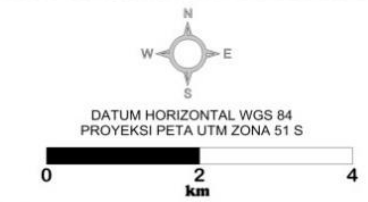

Keterangan :

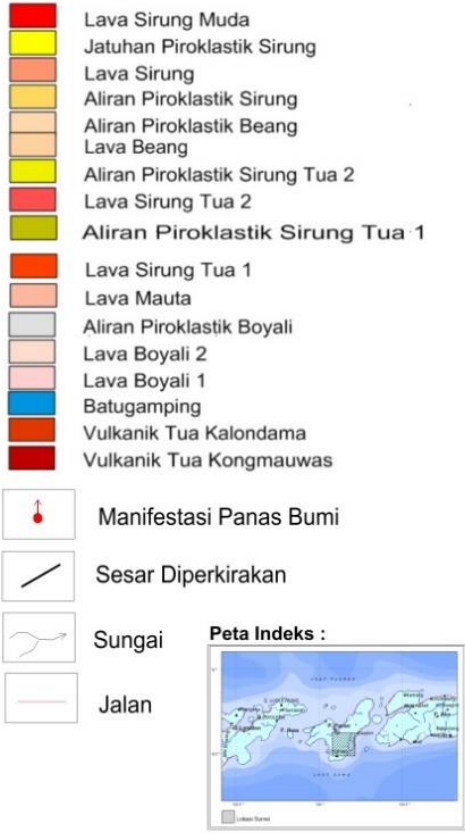

Gambar 2. Peta geologi daerah Pantar, Provinsi Nusa Tenggara Timur (modifikasi dari Hadi \& Kusnadi, 2015)

\section{METODE}

Metode MT digunakan untuk mengetahui informasi bawah permukaan berdasarkan variasi nilai tahanan jenis batuan. Sedangkan metode gaya berat digunakan untuk mengetahui variasi nilai densitas batuan bawah permukaan. Kedua metode ini dapat menggambarkan informasi struktur bawah permukaan yang berkembang di area panas bumi baik itu struktur lokal maupun struktur regional. Struktur-struktur geologi yang teridentifikasi dari hasil geofisika akan dianalisis korelasinya dengan sistem panas bumi. Kedua metode ini juga bisa menggambarkan variasi sifat fisis seperti densitas atau tahanan jenis secara lateral yang diharapkan bisa dijadikan acuan dalam penentuan lapisan reservoir panas bumi. Kombinasi kedua metode geofisika ini diharapkan dapat menggambarkan informasi struktur bawah permukaan yang berasosiasi dengan sistem panas bumi.

\section{Magnetotellurik (MT)}

Metode ini merupakan metode geofisika yang memanfaatkan medan elektromagnetik alami pada selang frekuensi $0,001-1000 \mathrm{~Hz}$. Medan elektromagnet (medan listrik dan medan magnet) diukur secara simultan pada selang waktu yang ditentukan. Hubungan antara medan listrik dan medan magnetik menghasilkan nilai tahanan jenis semu dan fasa (Chave \& Weidelt, 2012).

Nilai tahanan jenis semu didapatkan dari rasio antara medan listrik dan medan maget. Perbandingan tersebut dikenal dengan persamaan Cagniard dan merupakan hasil dari penurunan persamaan Maxwell dalam asumsi bidang 


\section{MAKALAH ILMIAH}

datar (Chave \& Weidelt, 2012). Tahanan jenis semu terdiri atas dua kurva tahanan jenis, yakni kurva tahanan jenis $x y(R h o-x y)$ dan kurva tahanan jenis $y x(R h o-y x)$. Data Time Domain Elektromagnetic (TDEM) digunakan dalam pemodalan sebagai pengkoreksi static shift data MT(Arnason, 2015).

Pemodelan data MT dilakukan dalam ranah 3-D dengan menggunakan perangkat lunak WS3DINV. Perangkat lunak ini dikembangkan oleh Dr. Weerachai Siripunvaraporn (Siripunvaraporn dkk., 2005). Pemodelan inversi 3-D data MT ini dilakukan dalam asumsi model topografi datar atau tanpa mempertimbangkan efek topografi. Efek topografi yang disebabkan oleh topografi permukaan yang tidak teratur dapat mengakibatkan interpretasi data MT yang kurang tepat (Nam dkk., 2008). Untuk menanggulangi hal ini, dilakukan koreksi topografi dengan menggunakan metode koreksi impedansi (Nam dkk., 2008) dalam pemodelan inversi 3-D.

Koreksi topografi dilakukan karena efek topografi 3-D bisa mendistorsi semua komponen tensor impedansi MT baik itu komponen diagonal maupun komponen off-diagonal. Hal ini terjadi karena medan listrik maupun medan magnet terdistorsi dalam semua polarisasi, sehingga semua komponen tensor impedansi harus digunakan untuk mendapatkan komponen off-diagonal yang tidak terdistorsi (Nam dkk., 2008). Dalam koreksi impedansi yang terdistorsi, konsep tensor terdistorsi juga digunakan yang awalnya dikembangkan sebagai koreksi hanya pada distorsi galvanic. Metode koreksi impedansi menghilangkan efek distorsi tensor impedansi MT dengan membuat hubungan yang linear terhadap tensor distorsi $2 \times 2$ (Nam dkk., 2008).

Aplikasi koreksi topografi juga efektif dalam mengidentifikasi target zona konduktif. Sedangkan jika tanpa koreksi, keberadaan zona konduktif tersebut tidak jelas. Koreksi topografi juga memberikan gambaran yang lebih jelas pada target yang resistif (Gambar 3). Sedangkan tanpa koreksi tersebut zona resistif tidak tergambarkan secara jelas dan memungkinkan anomali palsu seperti di target konduktif (Nam dkk., 2008). Berdasarkan gambar tersebut, dapat diasumsikan bahwa aplikasi koreksi topografi pada data MT akan memberikan hasil yang lebih jelas.

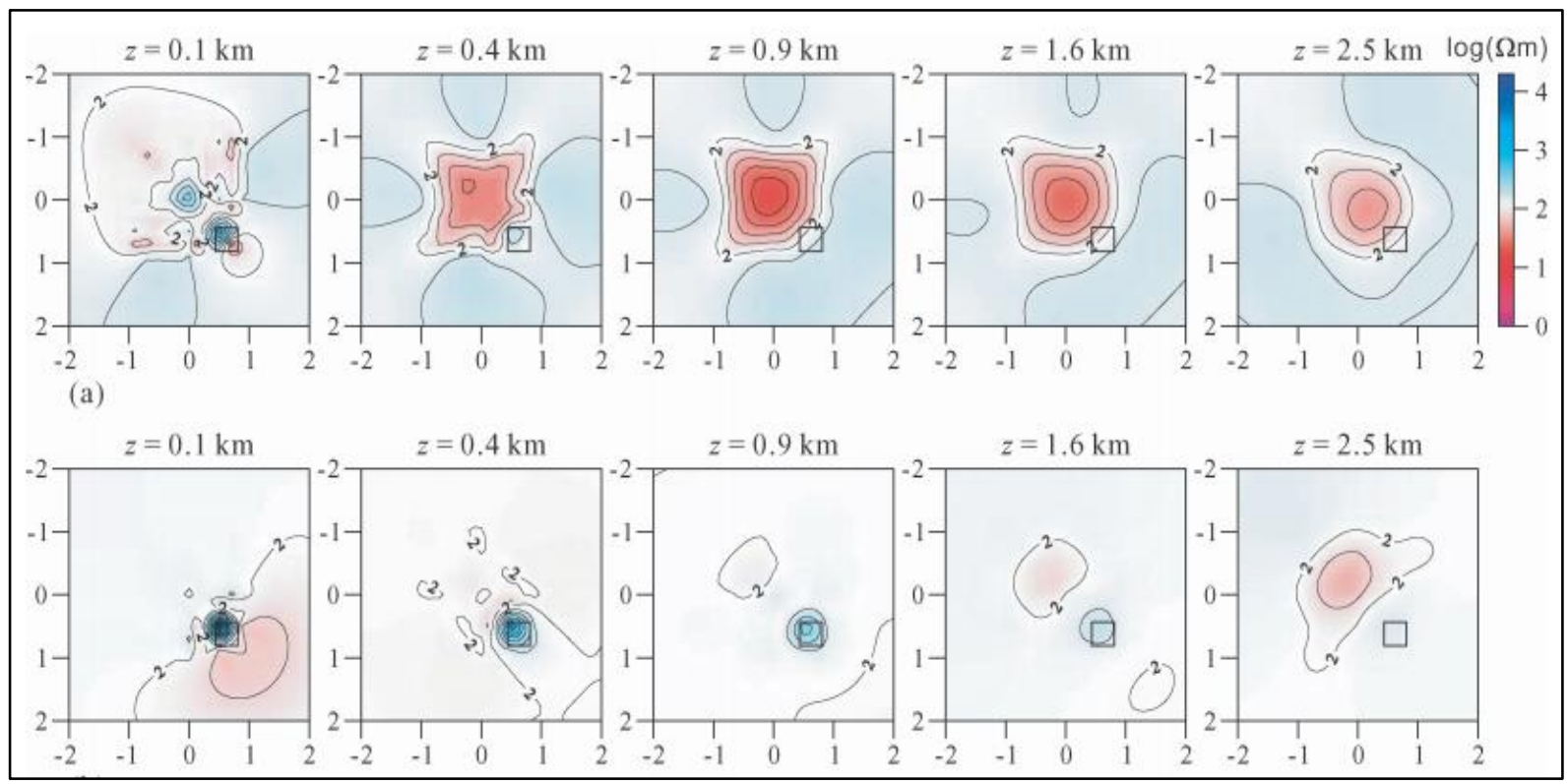

Gambar 3. Bagian (a) menunjukkan hasil inversi tanpa koreksi topografi sedangkan bagian

(b) menunjukkan hasil inversi dengan koreksi topografi. Kotak kecil dalam peta menunjukkan target resistif (Nam dkk.,2008). 


\section{Gaya Berat}

Data gaya berat yang terukur di lapangan dikoreksi dengan berbagai macam koreksi seperti koreksi pasang surut, koreksi drift, koreksi lintang, koreksi udara bebas, koreksi medan dan koreksi Bouguer dengan densitas 2,6 $\mathrm{gr} / \mathrm{cm}^{3}$. Koreksikoreksi ini dilakukan untuk mendapatkan nilai anomali Bouguer. Nilai anomali Bouguer tersebut merefleksikan variasi rapat massa yang terdapat pada suatu daerah dengan daerah sekelilingnya ke arah lateral maupun ke arah vertikal.

Untuk mendapatkan target anomali, anomali Bouguer dipisahkan menjadi anomali regional dan anomali residual (Gambar 4 A). Dalam pemisahan anomali ini, beberapa metode yang bisa dilakukan diantaranya kontinuasi keatas (upward continuation) (Ivan, 1986) dan trend surface analysis (Obasi dkk., 2016). Setelah dilakukan pemisahan anomali regional dan residual, analisis first vertical derivative (fvd) dan first horizontal derivative (fhd) dilakukan untuk menarik kelurusan struktur geologi (Gambar 4 B). Penarikan struktur lebih mudah dilakukan dengan menggunakan analisis first horizontal derivative karena struktur diindikasikan dengan nilai tinggi (puncak) (Sugianto dkk., 2017). Sedangkan dalam fvd struktur diindikasikan dengan batas antara nilai rendah (lembah) dan nilai tinggi (puncak).

Metode analisis struktur 3-D Basemen mengestimasi kedalaman dari batuan basement dengan asumsi komponen gelombang panjang (Long wave) dari anomali Bouguer yang disebabkan oleh relief batuan basement dan formasi geologi yang terdiri atas 2 lapisan (batuan basement dan lapisan diatasnya). Relief batuan basement diperkirakan dengan setset prisma yang gaya tarikan prismaprisma tersebut dihitung di atas permukaannya. Penjumlahan dari gaya tarik menarik prisma tersebut merupakan anomali yang terhitung di permukaan. Perkiraan kedalaman relief basement ditentukan berdasarkan perbedaan antara anomali pengamatan (observed anomaly) dan anomali penghitungan (calculated anomaly). Semakin kecil perbedaannya semakin tepat estimasi kedalaman relief basement (Dhaoui \& Gabtni, 2014).

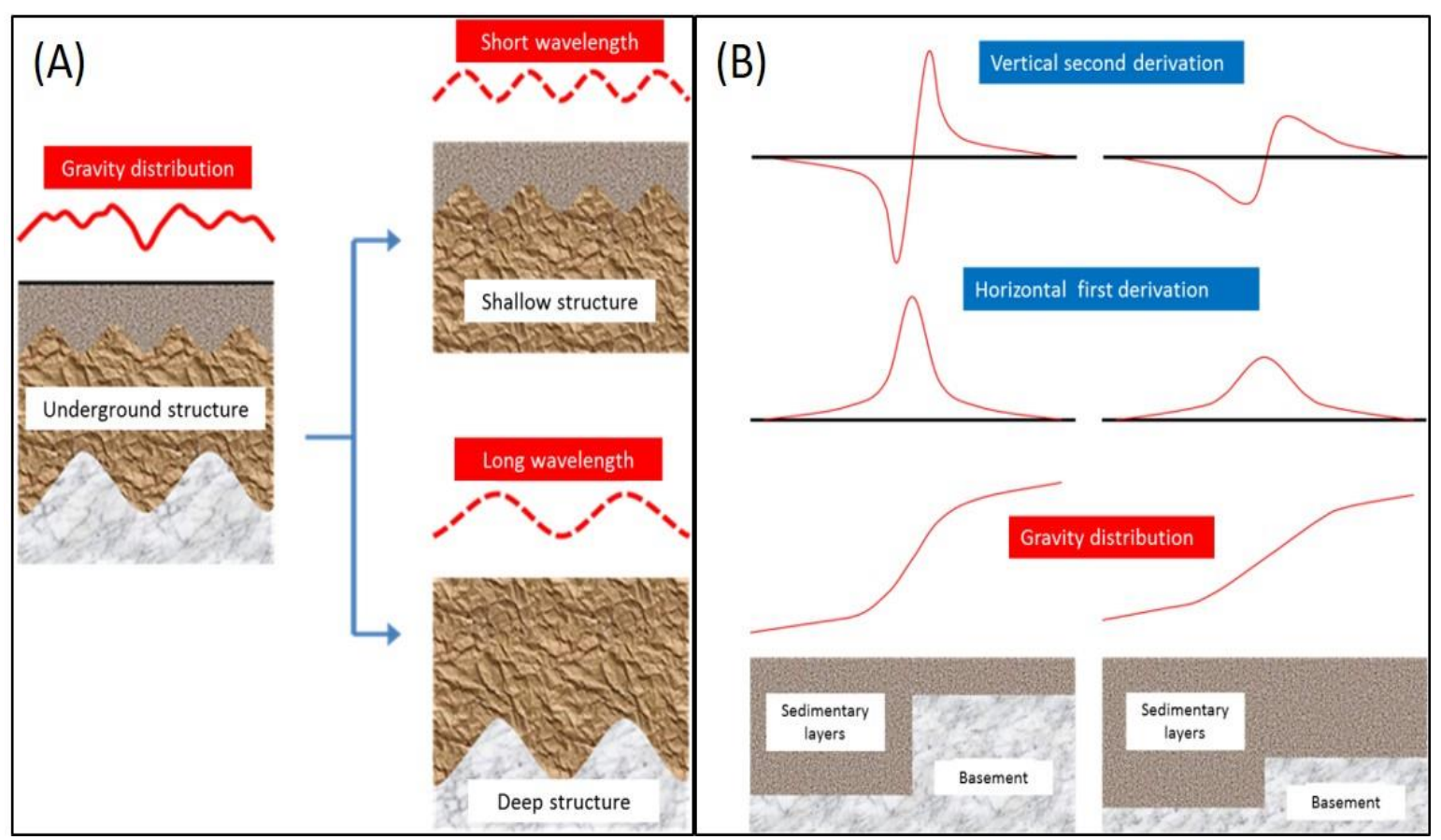

Gambar 4. Ilustrasi anomali gaya berat dari struktur bawah permukaan (A) dan ilustrasi turunan vertikal dan turunan horizontal $(B)$ 


\section{MAKALAH ILMIAH}

\section{HASIL DAN DISKUSI}

\section{Magnetotelurik (MT)}

Kurva MT sebelum dilakukan koreksi topografi dan setelah koreksi topografi menunjukkan adanya perbedaan terutama pada frekuensi rendah dibawah $1 \mathrm{~Hz}$. Pada stasiun pengukuran MT yang berada pada topografi tinggi seperti puncak gunung atau bukit, akan memberikan efek nilai anomali tinggi (Nam dkk., 2008). Beberapa contoh data MT yang berada pada topografi tinggi ditunjukkan dalam Gambar 5, dimana nilai tahanan jenis semu setelah dikoreksi topografi lebih besar dibandingkan sebelum koreksi topografi.

Data MT yang telah dikoreksi topografi kemudian dimodelkan dengan menggunakan perangkat lunak WS3-DMT dengan parameter yang sama dengan pemodalan inversi 3-D topografi datar (tanpa topografi). Hasilnya kemudian ditunjukkan dalam peta tahanan jenis perkedalaman dan penampang tahanan jenis. Hasil tersebut dibandingkan dengan pemodelan MT dengan aplikasi koreksi topografi dengan yang tanpa koreksi topografi.

Pada daerah panas bumi Pantar, area Gunung Beang memiliki perbedaan topografi yang signifikan (kotak biru pada Gambar 6 dan Gambar 7). Pada kedalaman 250 meter belum terlihat perbedaan yang signifikan antara hasil sebelum koreksi topografi dan setelah koreksi. Pada kedalaman ini, didominasi oleh sebaran tahanan jenis rendah $<10$ Ohmmeter yang bagian tengah ke arah utara diperkirakan merupakan respon dari batuan yang berfungsi sebagai caprock. Pada kedalaman 500 meter, sebaran tahanan jenis sebelum dan setelah koreksi topografi masih menunjukkan pola sebaran yang sama. Pada dua model (inversi 3-D sebelum dan setelah koreksi) ini mulai menunjukkan kenaikan nilai tahanan jenis (tahanan jenis medium 10 - 30 Ohmmeter). Nilai tahanan jenis sedang ini diperkirakan sebagai zona transisi antara caprock dan reservoir dari sistem panas bumi di daerah ini.

Pada kedalaman 750 meter, nilai tahanan jenis medium mulai menyebar pada semua model hasil inversi. Di dalam kotak birunya, hasil dari inversi 3-D tanpa topografi memiliki nilai tahanan jenis rendah $<10$ Ohmmeter sedangkan hasil dari inversi 3D koreksi topografi menunjukkan nilai yang lebih tinggi >10 Ohmmeter. Nilai tahanan jenis sedang di kedalaman ini masih diperkirakan sebagai zona transisi antara caprock dan reservoir.

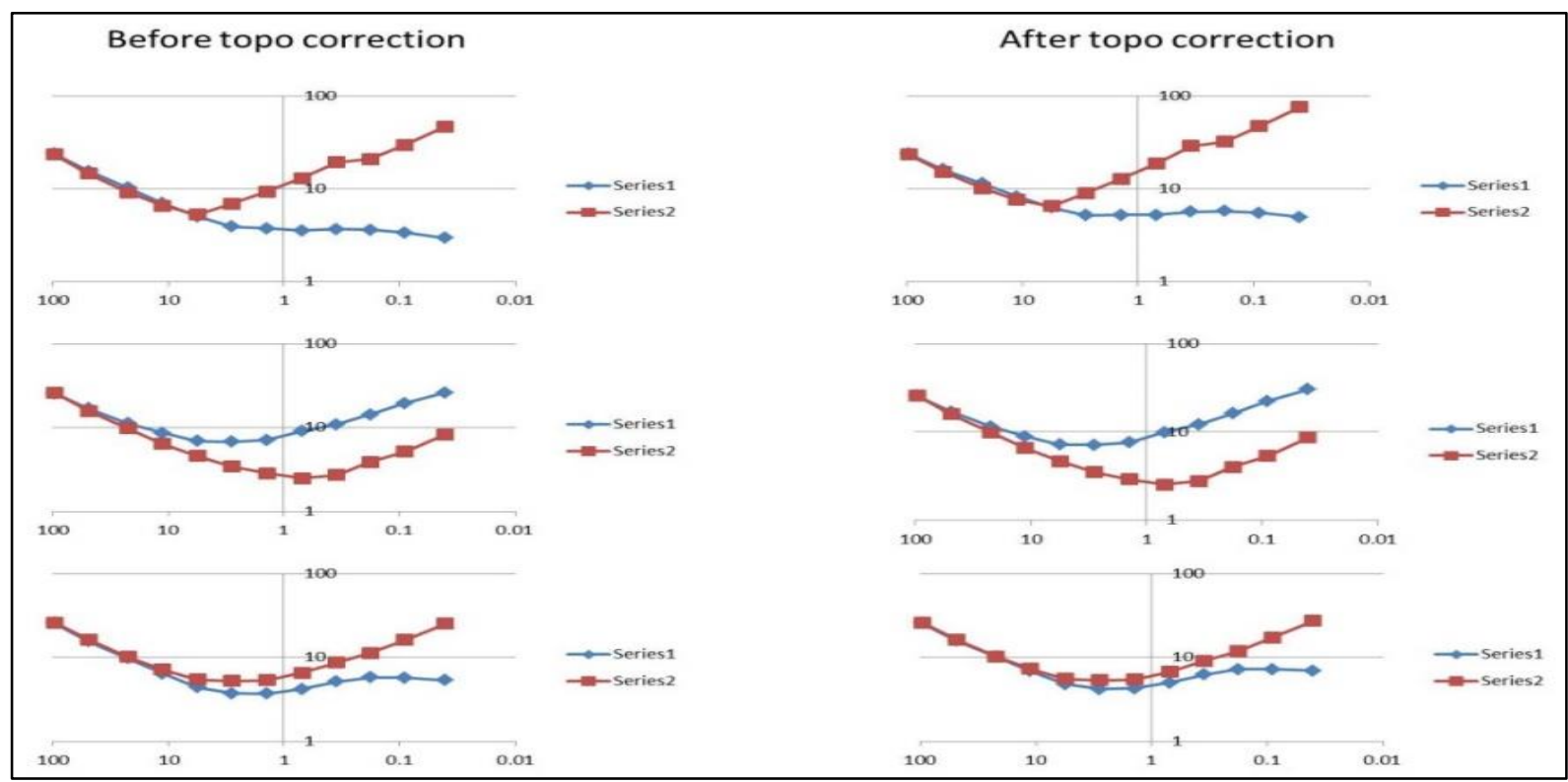

Gambar 5. Kurva MT sebelum koreksi topografi (kiri) dan setelah koreksi topografi (kanan) 


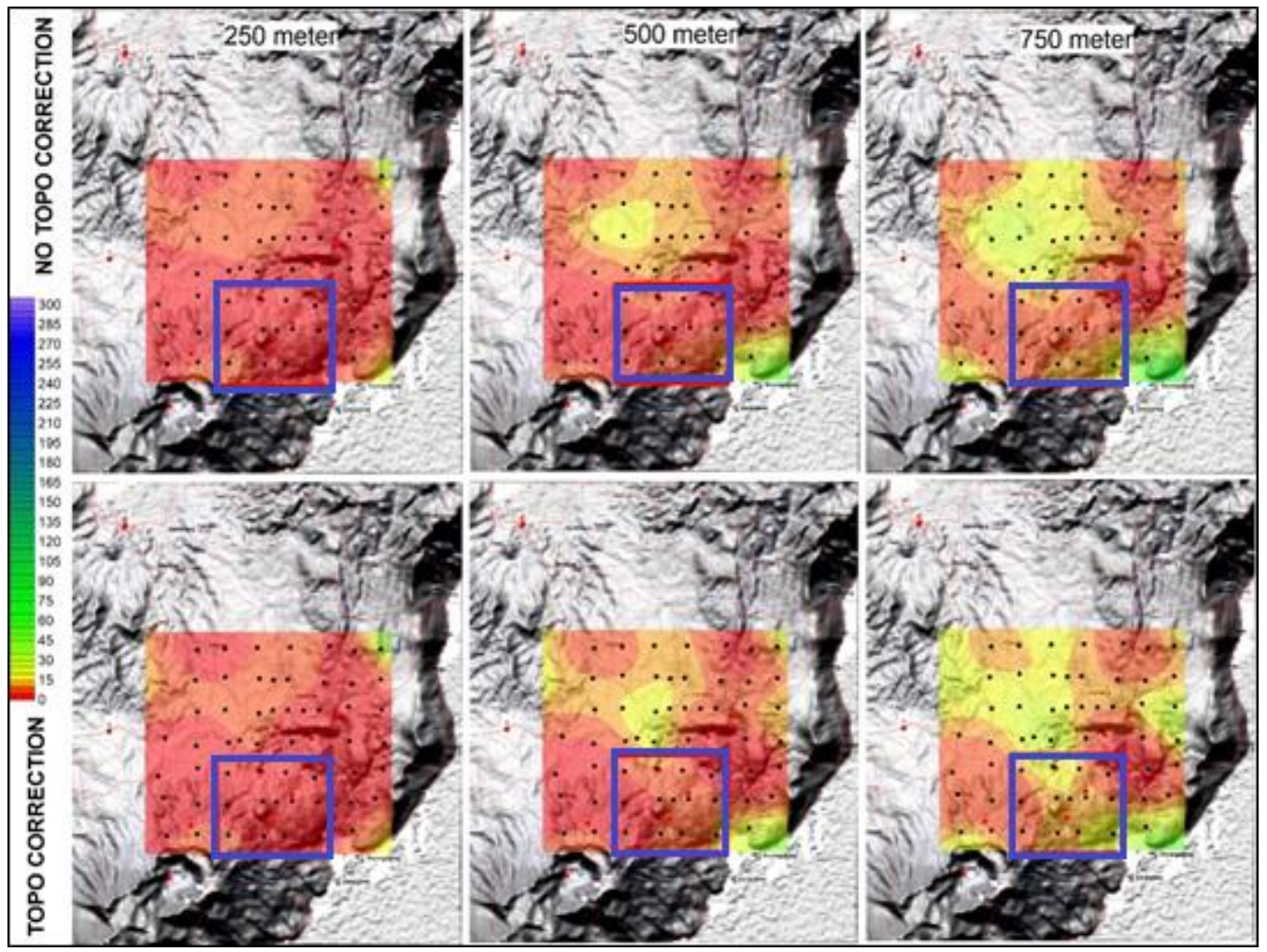

Gambar 6. Perbandingan peta tahanan jenis berbagai kedalaman antara 3-D tanpa koreksi topografi (atas) dan 3-D dengan koreksi topografi (bawah), kotak biru menunjukkan target anomali kedalaman 250 meter s.d. 750 meter

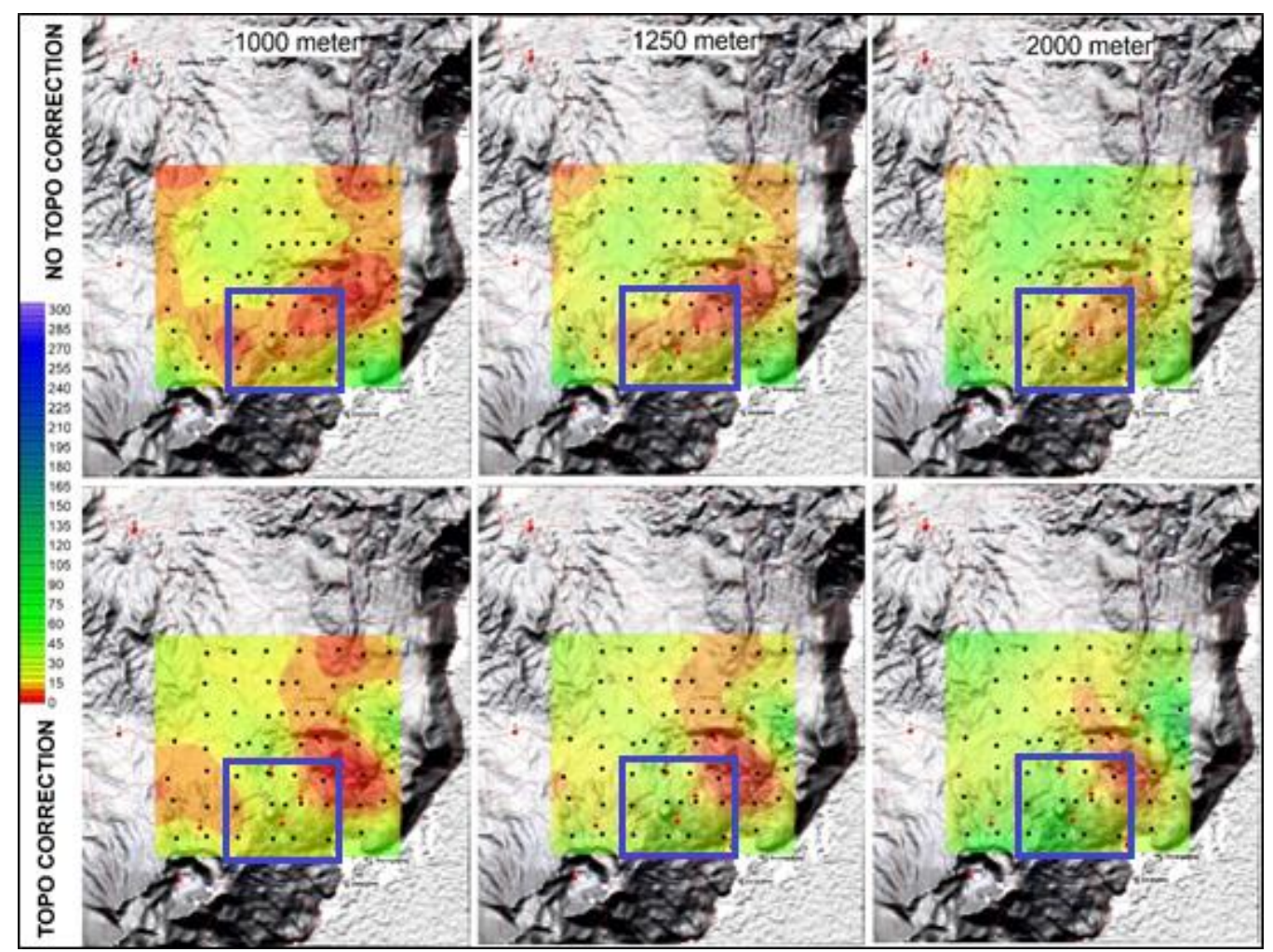

Gambar 7. Perbandingan peta tahanan jenis berbagai kedalaman antara inversi 3-D tanpa koreksi topografi dan 3-D dengan koreksi topografi. Kotak biru menunjukkan target anomali kedalaman 1000 meter s.d. 2000 meter 
Nilai tahanan jenis sedang yang lebih tinggi (30-100 Ohmmeter) muncul di kedalaman 1000 dan 1250 meter. Nilai sedang ini diperkirakan merupakan top reservoir dari sistem panas bumi di Pulau Pantar. Di bagian dalam kotak biru terlihat perbedaan yang jelas antara hasil pemodelan 3-D inversi tanpa topografi dan setelah koreksi topografi. Pada model 3-D tanpa topografi menunjukkan nilai tahanan jenis rendah $<10$ Ohmmeter sedangkan model 3-D koreksi topografi menunjukkan nilai yang lebih besar $>10$ Ohmmeter. Hasil dari pemodelan 3-D dengan koreksi topografi menunjukkan adanya korelasi antara manifestasi di bagian tengah area dengan manifestasi di bagian selatan/tenggara (mata air panas Beang). Sedangkan hasil dari pemodelan tanpa topografi menunjukkan adanya pembatas antara manifestasi di bagian tengah dengan manifestasi di bagian selatan/tenggara.

Hasil dari pemodelan inversi dari kedua teknik tersebut pun disajikan dalam bentuk model penampang (Gambar 8). Tiga buah model penampang dibuat dengan arah barat-timur yang memotong beberapa manifestasi panas bumi. Pada kedua gambar tersebut terdapat beberapa perbedaan hasil dari inversi ini. Pada model hasil inversi 3-D setelah koreksi topografi memiliki nilai tahanan jenis yang lebih tinggi dibandingkan jenis inversi 3-D tanpa koreksi topografi pada kedalaman lebih dari 1500 meter. Pada penampang lintasan 2 (L2) terlihat perbedaan yang signifikan diantara jenis model. Lintasan ini melalui Gunung Beang yang memiliki topografi bervariasi. Variasi topografi merupakan salah satu penyebab adanya perbedaan nilai antara kurva tahanan jenis $x y(R h o-x y)$ dan kurva tahanan jenis $y x$ (Rho-yx). Perbedaan ini yang dikenal dengan istilah shifting.

Hasil dari inversi 3-D setelah koreksi topografi di lintasan ini menggambarkan hasil yang lebih baik mengenai keberadaan sistem panas bumi di daerah ini. Pada area sekitar manifestasi panas bumi menunjukkan pola updome yang jelas. Sedangkan hasil inversi 3-D tanpa koreksi topografi tidak menunjukkan pola yang seperti ini. Keberadaan nilai tahanan jenis medium yang berada di bawah nilai tahanan jenis rendah yang membentuk pola updome biasanya mengindikasikan adanya keberadaan reservoir dari sistem panas bumi.

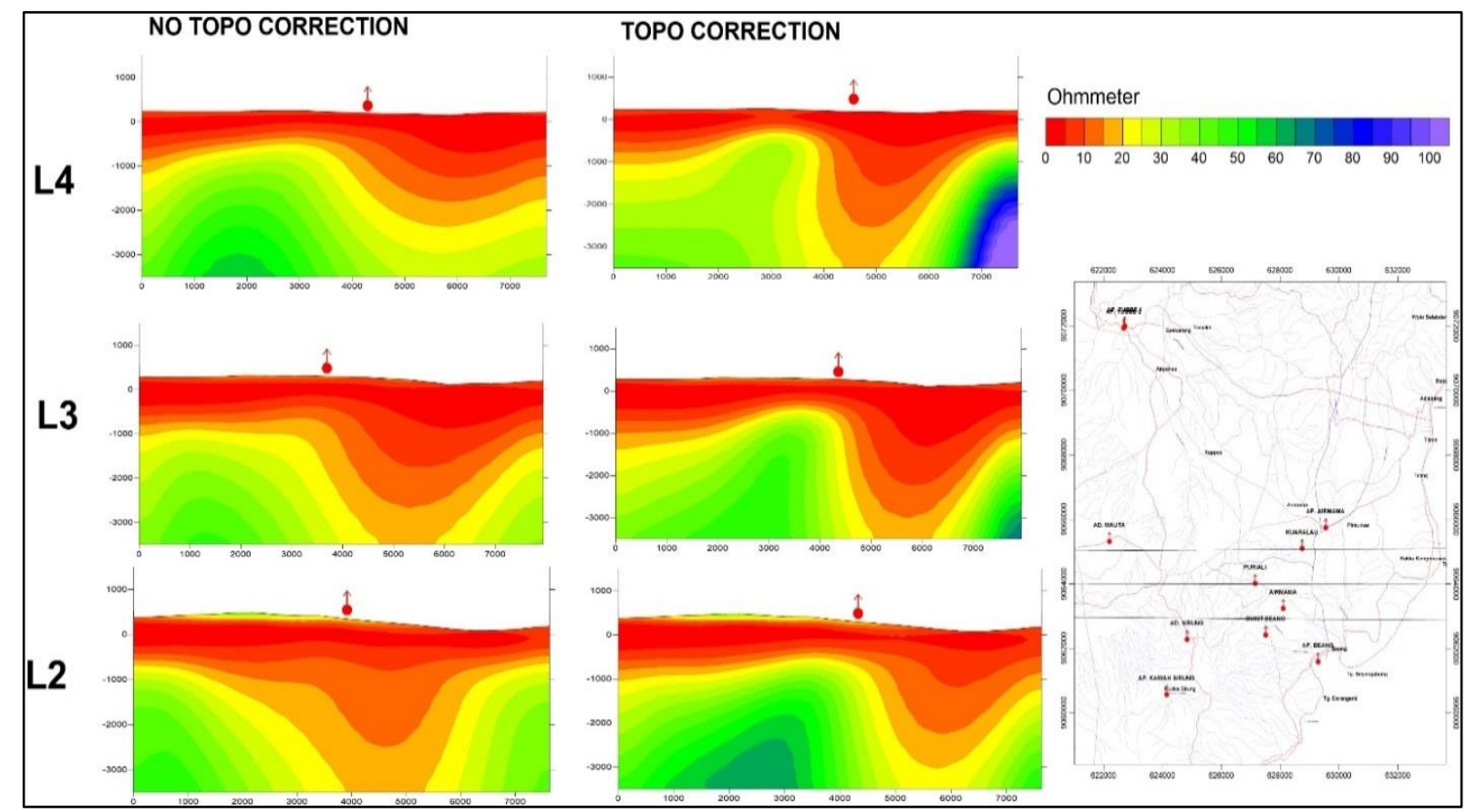

Gambar 8. Perbandingan penampang MT antara inversi 3-D tanpa koreksi topografi dan 3-D dengan koreksi topografi 


\section{Gaya Berat}

Pengolahan data gaya berat menghasilkan peta anomali Bouguer yang kemudian di pisahkan untuk mendapatkan anomali regional dan anomali residual. Anomali regional digunakan untuk mengetahui struktur bawah permukaan di bagian dalam sedangkan anomali residual digunakan untuk mengetahui struktur bawah permukaan yang lebih dangkal.

Pada makalah ini teknik penapisan menggunakan trend surface analysis dan upward continuation (kontinuasi keatas). Hasil dari proses penapisan metode trend surface analysis power 2 dapat dilihat dalam Gambar 9 (A). Pada peta anomali regional menunjukkan nilai anomali tinggi berada di bagian selatan dan utara sedangkan nilai anomali rendah berada di bagian barat dan timur. Pola tersebut menunjukkan adanya kelurusan berarah baratdaya-timurlaut. Peta anomali residual menunjukkan pola yang relatif sama dengan peta anomali Bouguer dimana anomali tinggi berada di sekitar manifestasi dan anomali rendah berada di bagian tenggara dan utara.

Hasil penapisan dengan menggunakan kontinuasi keatas terlihat pada Gambar 9 (B). Kontinuasi keatas pada ketinggian 3000 meter menunjukkan gambaran anomali yang relatif mirip dengan peta anomali regional. Anomali tinggi berada di bagian utara dan selatan sedangkan anomali rendah berada di bagian barat dan timur. Kontras anomali rendah dan tinggi membentuk kelurusan yang berarah baratdaya-timurlaut. Kontinuasi keatas pada ketinggian 100 meter menunjukkan hasil anomali yang relatif mirip dengan pola anomali Bouguer. Pengurangan anomali hasil kontinuasi keatas pada ketinggian 100 meter terhadap hasil dari kontinuasi keatas pada ketinggian 3000 meter memberikan gambaran anomali residual.

Peta anomali residual yang didapatkan dari kedua teknik penapisan diatas kemudian disandingkan (Gambar 10Gambar ). Hasil dari kedua teknik penapisan tersebut memiliki kesamaan pola anomali tinggi yang berada di bagian tengah (sekitar manifestasi) memanjang ke arah timurlaut. Zona anomali tinggi ini diapit oleh zona anomali rendah di bagian baratlaut dan tenggara. Kemudian dilakukan analisis first horizontal derivative (FHD) pada kedua peta anomali residual tersebut agar bisa memberikan gambaran struktur hasil dari kontras anomali tinggi dan anomali rendah Gambar 11. menunjukkan hasil FHD yang didapatkan dari trendsurface analysis lebih baik kontrasnya dibandingkan hasil dari kontinuasi keatas. Meskipun kedua hasil analisis FHD tersebut secara umum menunjukkan kontras anomali yang hampir sama. Dari peta FHD ini bisa digambarkan kelurusannya untuk memperkirakan struktur di daerah penelitian.

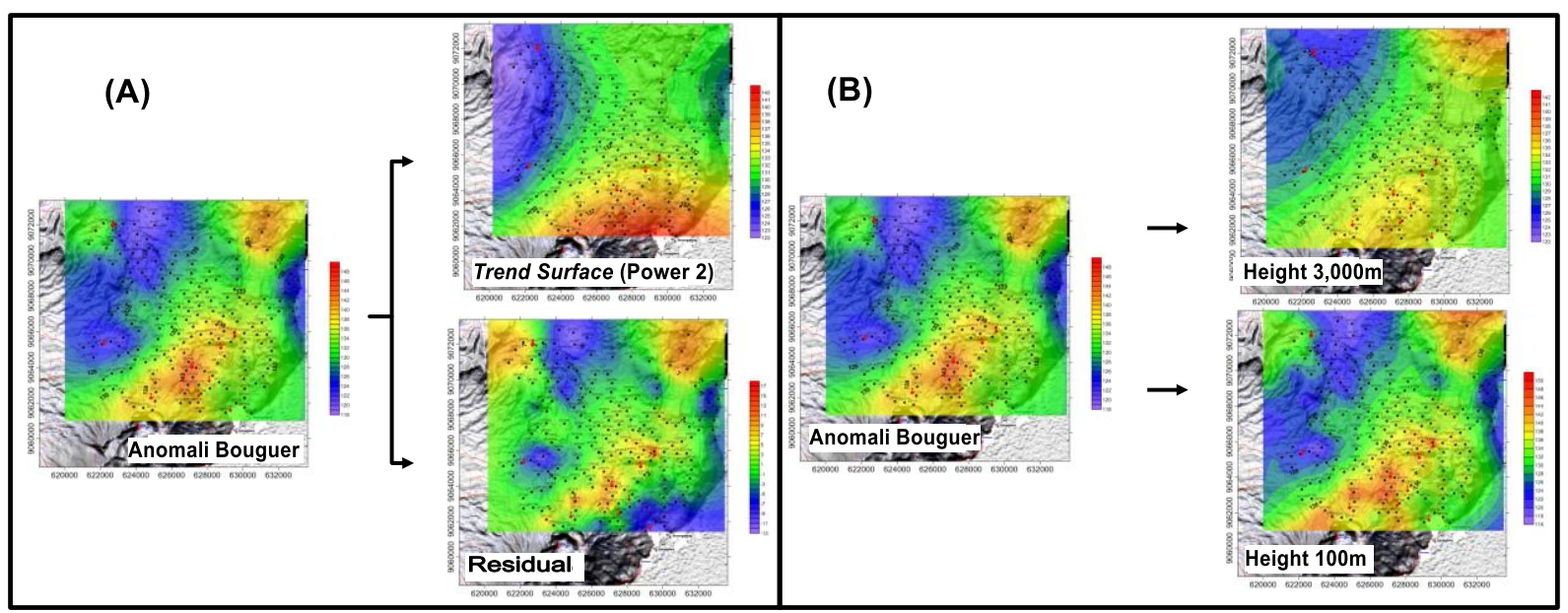

Gambar 9. Hasil trend surface analysis (A) dan upward continuation (B) 


\section{MAKALAH ILMIAH}

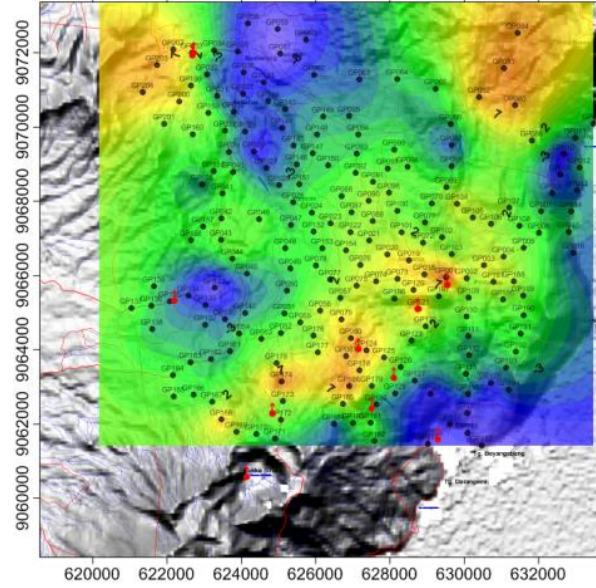

Hasil trend surface analysis

(power 2)

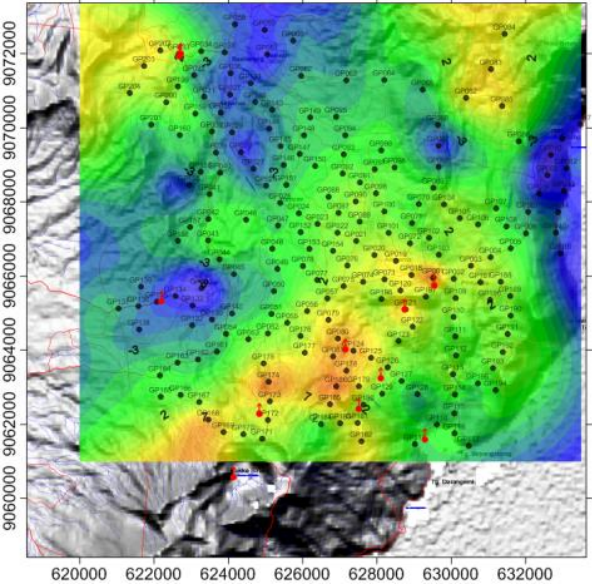

Hasil upward filter analysis

$(100 \sim 3,000 \mathrm{~m})$

Gambar 10. Perbandingan antara trend surface analysis dan upward continuation

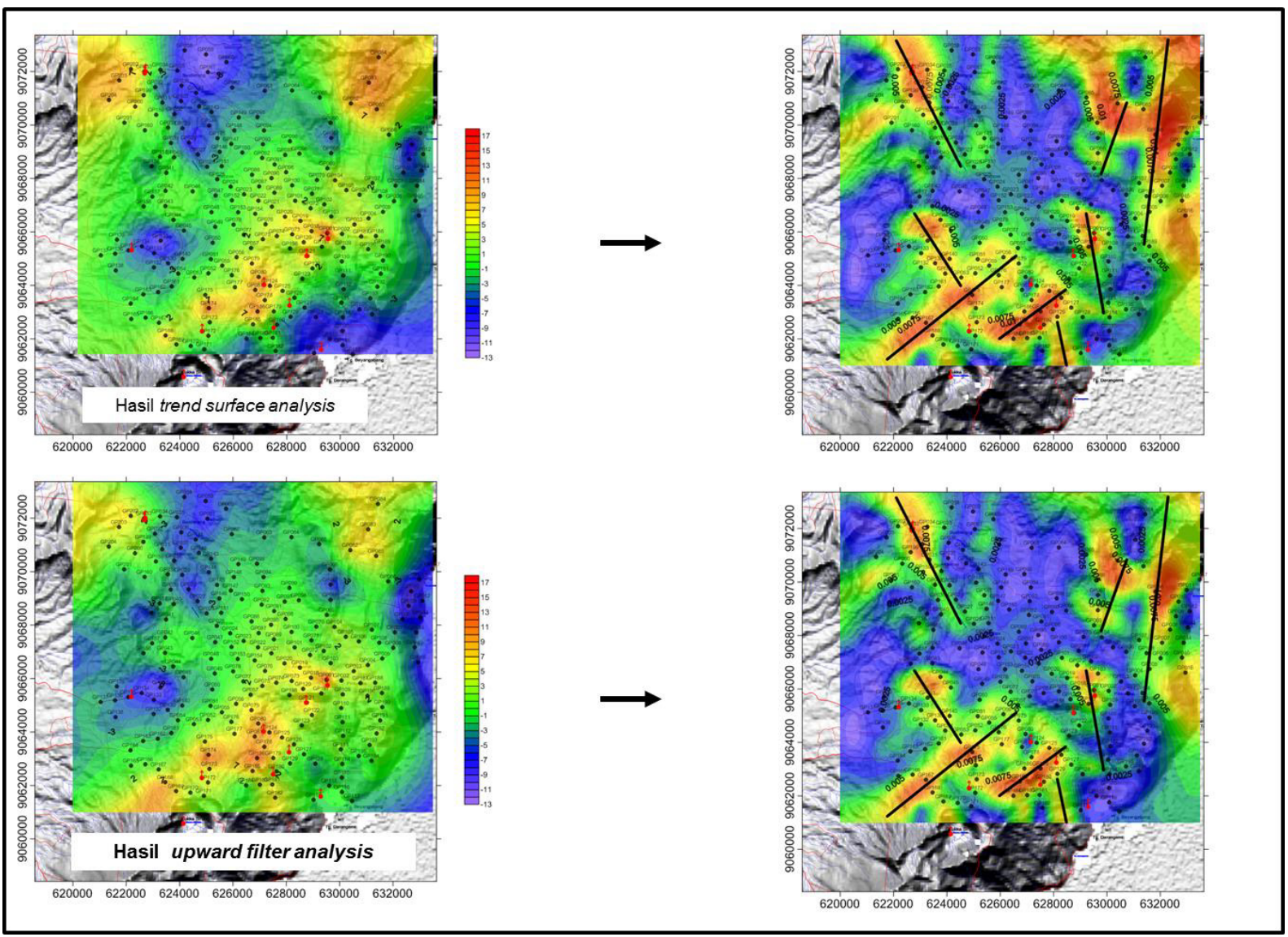

Gambar 11. Perbandingan antara hasil First Horizontal derivative dari trend surface analysis dan Upward Continuation

Untuk lebih memastikan struktur kelurusan di daerah penelitian ini, dilakukan juga analisis struktur basement 3-D yang bisa dilihat dalam Gambar 12. Hasil perhitungan nilai gravitasi dari analisis struktur basement 3-D memberikan hasil yang tidak begitu jauh berbeda dengan anomali Bouguer. Estimasi kedalaman basement bervariasi pada elevasi 400 meter hingga elevasi -1200 meter (Gambar 13). Hasil ini sesuai dengan informasi kondisi geologinya dimana batuan basementnya 


\section{MAKALAH ILMIAH}

merupakan batuan vulkanik tua yang tersingkap di permukaan di sekitar manifestasi. Pola kelurusan struktur yang dihasilkan dari analisis FHD dan analisis struktur basement 3-D memiliki pola yang hampir sama dengan struktur geologi pada peta geologi di daerah ini.
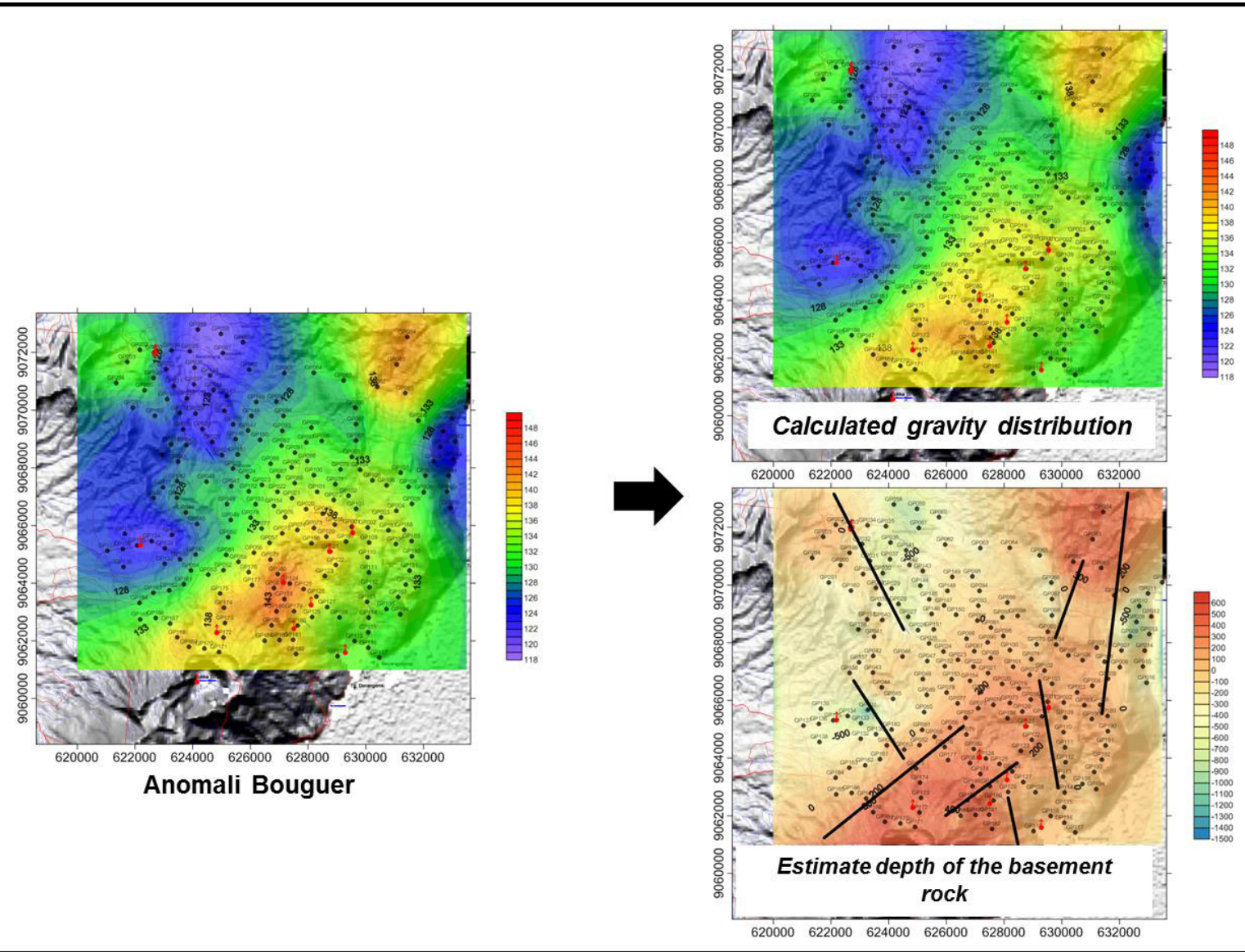

Gambar 12. Hasil analisis struktur basement 3-D

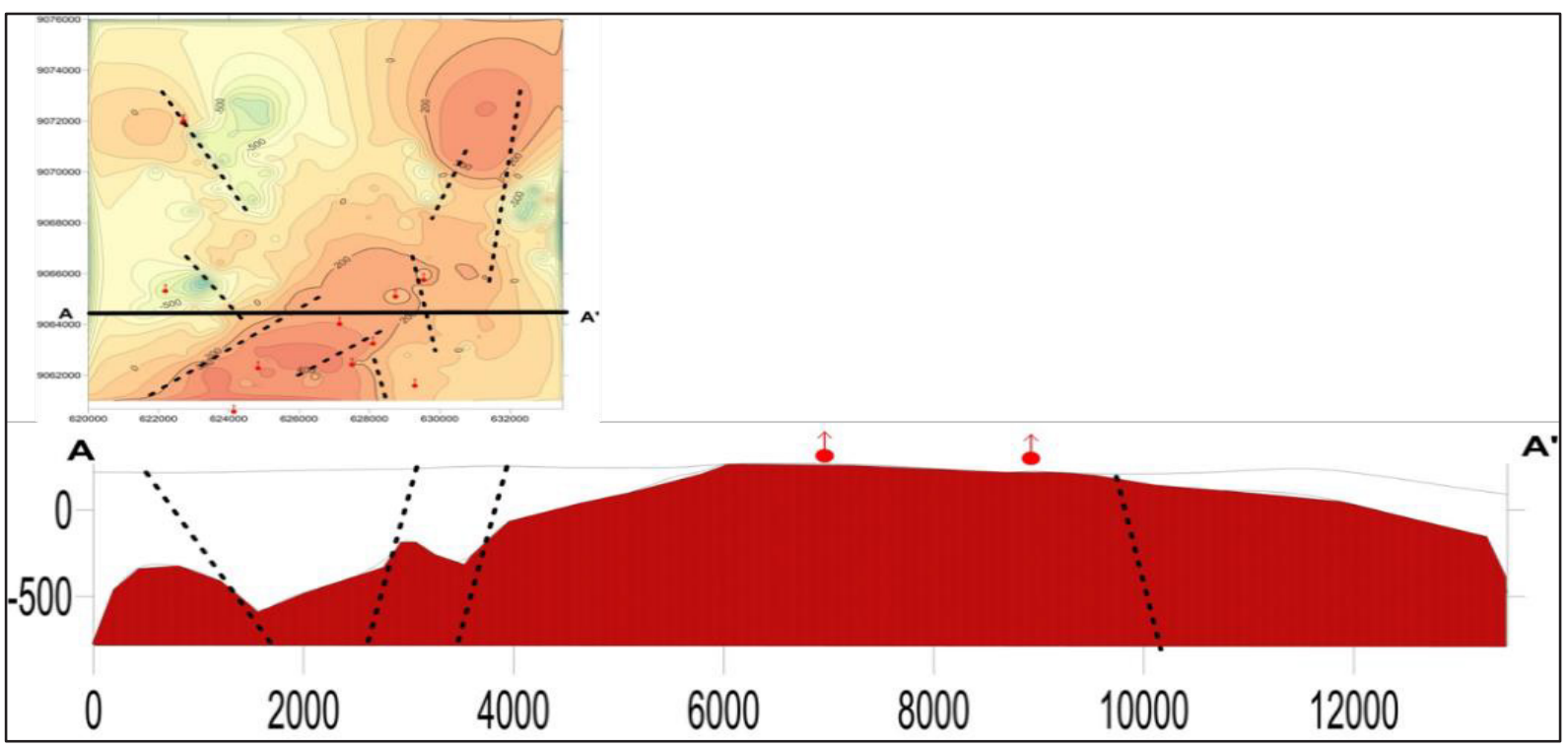

Gambar 13. Penampang struktur basement daerah Pantar 


\section{Analisis Terpadu}

Hasil pemodelan MT pada kedalaman dangkal menunjukkan adanya tahanan jenis rendah yang konsisten di sekitar manifestasi panas bumi Pantar. Tahanan jenis rendah ini termodelkan oleh MT pada kedua teknik (koreksi topografi /non koreksi). Anomali tahanan jenis ini diperkirakan merupakan batuan teralterasi dengan tingkat alterasi intensif terutama di sekitar Bukit Beang, Puriali dan Air Mama (Gambar 6, 7 dan 8).

Perbedaan pola pemodelan tahanan jenis MT antara kedua teknik mulai terlihat pada kedalaman 750 meter di sekitar Gunung Beang. Pada kedalaman tersebut struktur tahanan tanpa koreksi topografi masih memodelkan nilai tahanan jenis rendah. sedangkan pada model dengan koreksi topografi nilai model tahanan jenis mulai memasuki nilai medium.

Ambiguitas hasil pemodelan merupakan problem besar menarik interpretasi sistem panas bumi. Kesalahan interpretasi akan berakibat fatal dalam rencana eksplorasi selanjutnya. Salah satu solusinya adalah perlu data kebumian lain sebagai bahan pertimbangan interpretasi. Hasil dari gaya berat dapat dijadikan bahan acuan untuk mengurangi ketidakpastian hasil MT.

Hasil gaya berat menunjukkan adanya anomali tinggi di sekitar Gunung/Bukit beang (Gambar 9 sampai 12). Anomali tinggi pada gaya berat mengindikasikan adanya densitas batuan yang relatif lebih tinggi dari lingkungan sekitarnya. Anomali ini konsisten terindikasi dengan hasil analisis data gaya berat berbagai teknik.

Kombinasi interpretasi hasil gaya berat memperkuat hasil dari model MT dengan koreksi topografi. Anomali tinggi dari gaya berat menunjukkan adanya densitas batuan tinggi yang diperkirakan sebagai sumber panas sistem panas bumi. Analisis ini memperkuat hasil MT dengan koreksi topografi yang menunjukkan adanya nilai tahanan jenis medium dan tinggi di area sekitar Gunung Beang. Model tahanan jenis tinggi tersebut diperkiraan sebagai zona transisi dan zona reservoir sistem panas bumi.

Berdasarkan hasil MT dengan koreksi topografi dan gaya berat dapat diinterpretasikan zona caprock dan zona reservoir sistem panas bumi Pantar. Tahanan jenis rendah dengan nilai $<10$ Ohmmeter diperkirakan sebagai batuan teralterasi kuat yang berperan sebagai lapisan penudung. Geometri lapisan ini diperkirakan sampai dengan kedalaman sekitar 750 meter dan terbentuk di area sekitar Gunung Beang ke arah utara dan timurlaut. Pada kedalaman 750-1000 meter diperkirakan merupakan zona transisi lapisan penudung dengan zona reservoir yang termodelkan dengan nilai tahanan jenis medium 10-30 Ohmmeter. Area sekitar ini diperkuat oleh data gaya berat dengan keberadaan anomali tinggi.

\section{KESIMPULAN}

Proses pengolahan dan pemodelan data MT dapat dilakukan dengan berbagai teknik seperti pemodelan 3-D tanpa melibatkan koreksi topografi atau dengan koreksi topografi. Hasil pemodelan yang diperoleh dari teknik tersebut memperlihatkan perbedaan yang tidak signifikan pada area dengan variasi topografi rendah (pedataran). Sedangkan pada area dengan variasi topografi tinggi terdapat perbedaan signifikan pada model tahanan jenis yang diperoleh di daerah Pantar.

Penggunaan data gaya berat sebagai metode kombinasi dapat memperkuat hasil yang diperoleh dari berbagai teknik proses pengolahan data MT. Hasil analisis gaya berat di daerah Pantar memperlihatkan hasil yang mendukung pemodelan menggunakan teknik inversi 3-D dengan koreksi topografi.

Kombinasi kedua hasil metode tersebut (gaya berat dan koreksi topografi) secara jelas menggambarkan informasi yang lebih baik mengenai keberadaan dari caprock 
atau lapisan penudung dan zona reservoir sistem panas bumi Pantar. Zona anomali tinggi yang termodelkan pada hasil MT dan juga pada hasil gaya berat mempertegas adanya tubuh vulkanik muda yang diinterpretasikan sebagai sumber panas sistem panas bumi.

Zona caprock termodelkan di area sekitar Gunung Beang sampai dengan kedalaman 750 meter. Zona transisi antara lapisan penudung dan zona reservoir diperkirakan berada pada kedalaman sekitar 750-1000 meter.

\section{UCAPAN TERIMA KASIH}

Penulis banyak mengucapkan terima kasih kepada Pusat Sumber Daya Mineral Batubara dan Panas Bumi, WestJec Japan, Kumamoto University dan New Energy Foundation Japan atas semua bantuannya. Terkhusus kepada Mr. Mitsuru Honda dan Dr. Saito dari WestJec yang telah memberikan izin dalam penggunaan program mereka.

\section{DAFTAR PUSTAKA}

Arnason, K. (2015). The Static Shift Problem in MT Soundings. Word Geothermal Congress. Melbourne: 2015.

Chave, A. D., \& Weidelt, P. (2012). The Theoritical Basis for Electromagnetic Induction. Dalam A. D. Chave, \& A. G. Jones, The Magnetotelluric Method (hal. 19-44). Cambridge: Cambridge University Press.
Dhaoui, M., \& Gabtni, H. (2014). Depth to basement analysis from gravity field over the Guelb Ahmer horst (Ghadames petroleum province, Southern Tunisia, North Africa). IOSR Journal of Applied Geology and Geophysics (IOSR-JAGG) vol 2 Issue 5, 122-127.

Hadi, M., \& Kusnadi, D. (2015). Survei Geologi dan Geokimia Daerah Panas Bumi Pantar, Kabupaten Alor, Nusa Tenggara Timur. Bandung: Pusat Sumber Daya Geologi.

Ivan, M. (1986). On The Upward Continuation of Potential Field Data Between Irregular Surfaces. Geophysical Prospecting, 735-742.

Nam, M., Kim, H., Song, Y., Lee, T., \& Suh, J. (2008). Three-dimensional topography corrections of magnetotelluric data. Geophys. J. Int.

Noya, Y., \& Koesoemadinata. (1991). Peta Geologi Regional Lembar Pantar dan Wetar. Bandung: Pusat Penelitian dan Pengembangan Geologi.

Obasi, A., Onwuemesi, A., \& Romanus, O. (2016). An Enhanced Trend Surface Analysis Equation for RegionalResidual Separation of Gravity Data. Journal of Applied Geophysics 135, 90-99.

Siripunvaraporn, W., Egbert, G., Lenbury, Y., \& Uyeshima, M. (2005). Threedimensional magnetotelluric inversion: data-space method. Physics of The Earth And Planetary Interiors, 3-14.

Sugianto, A., Takodama, I., \& Rahadinata, T. (2017). Identifikasi Struktur Sistem Panas Bumi Pantar Berdasarkan Analisis Gradien Horizontal dan Pemodelan 3D Data Gaya Berat. Buletin Sumber Daya Geologi Vol.12 no.2, 135-143.

\begin{tabular}{|ll|}
\hline Diterima & $:$ 28 Oktober 2019 \\
Direvisi & $: 13$ November 2019 \\
Disetujui & $: 30$ November 2019 \\
\hline
\end{tabular}

